\title{
A Novel Candidate Molecule in the Pathological Grading of Gliomas: ELABELA
}

\author{
Gokhan ARTAS ${ }^{1}$, Sait OZTURK², Tuncay KULOGLU ${ }^{3}$, Adile Ferda DAGLI' ${ }^{1}$, Murat GONEN ${ }^{4}$, Hakan ARTAS 5 , \\ Suleyman AYDIN ${ }^{6}$, Fatih Serhat EROL ${ }^{2}$
}

${ }^{1}$ Firat University, School of Medicine, Department of Pathology, Elazig, Turkey

${ }^{2}$ Firat University, School of Medicine, Department of Neurosurgery, Elazig, Turkey

${ }^{3}$ Firat University, School of Medicine, Department of Histology, Elazig, Turkey

${ }^{4}$ Firat University, School of Medicine, Department of Neurology, Elazig, Turkey

${ }^{5}$ Firat University, School of Medicine, Department of Radiology, Elazig, Turkey

${ }^{6}$ Firat University, School of Medicine, Department of Biochemistry, Elazig, Turkey

\section{ABSTRACT}

AIM: To investigate the possible role of ELABELA (ELA) in the histopathological grading of gliomas.

MATERIAL and METHODS: We retrospectively assessed pathological specimens of patients who underwent surgery for intracranial space-occupying lesions. Only primary glioma specimens were included in this study. We enrolled 11 patients histologically diagnosed with low-grade glioma and 22 patients with high-grade glioma. The ELA antibody was applied to 4-6- $\mu m$-thick sections obtained from paraffin blocks. Histoscores were calculated using the distribution and intensity of staining immunoreactivity. An independent sample t-test was used for two-point inter-group assessments, whereas one-way analysis of variance was used for the other assessments. $\mathrm{p}<0.05$ was considered statistically significant.

RESULTS: The histoscores of the control brain, low-grade glioma, and high-grade glioma tissues were found to be $0.08,0.37$, and 0.92, respectively. The difference in ELA immunoreactivity between the control brain tissue and glioma tissue was statistically significant $(p<0.05)$. In addition, a statistically significant increase was observed in ELA immunoreactivity in high-grade glioma tissues compared with that in low-grade glioma tissues $(p<0.05)$.

CONCLUSION: ELA has an angiogenetic role in the progression of glial tumors. ELA, which is an endogenous ligand of the apelin receptor, activates the apelinergic system and causes the progression of glial tumors. Further studies with a large number of patients are necessary to investigate the angiogenetic role of ELA in glial tumors.

KEYWORDS: Apelin, Apelin receptor, Astrocytoma, Elabela, Glioma

\section{INTRODUCTION}

$\mathrm{G}$ liomas are the most common primary malignant central nervous system (CNS) tumors in adults. They are either astrocytic, oligodendrocytic, or a combination of these two cell types (14). In addition, gliomas are characterized by genetic and morphological complexities and can diffusely infiltrate into the normal brain parenchyma $(13,17)$.
ELABELA (ELA) is an endogenous peptide ligand of the apelin receptor (AR) and plays a critical role in zebrafish embryonic development $(7,30)$. Reportedly, AR was first cloned as an orphan G-protein-coupled receptor (GPCR) and has 30\% homology with angiotensin receptor-1 (29). In addition, its ligand, apelin, was isolated from bovine stomach extract in 1998 (37). The AR is a class-A GPCR that was first described by O'Dowd (29). Both apelin and its receptor are expressed 
in various eukaryotes, including humans, and some other studies have also been conducted in cells or tissue cultures of rodent or other animal models. High levels of apelin have been observed in the CNS, and both its receptor and ligand are widely present throughout the peripheral tissue $(2,9,19)$.

Apelin regulates numerous different physiological functions such as fluid homeostasis, angiogenesis, and energy metabolism $(1,22,34)$. Reportedly, apelin acts as a vascular chemoattractant molecule as the vascular endothelial growth factor (VEGF) (31), and induces angiogenesis in the progression of tumors $(20,21,24)$. The activation of VEGF signaling stimulates new vessel formation for the growing tumor, as these new vessels provide oxygen and nutrients for tumor growth (15). Thus, ELA is a hormone that stimulates angiogenesis and, at the same time, provides homeostasis of energy metabolism through the apelinergic system.

Because high-grade gliomas are still one of the most lethal forms of cancer, it is imperative to establish possible molecular mechanisms underlying their growth/progression patterns. Thus, the present study aimed to investigate the possible role of ELA in the histopathological grading of gliomas that are radiologically and pathologically diagnosed.

\section{- MATERIAL and METHODS}

\section{Patient Selection}

This study was approved by Firat University Ethical Committee (Date: 29.09.2016, Approval No: 14-07). We retrospectively assessed pathological specimens of patients who underwent surgery for intracranial space-occupying lesions between 2015 and 2017. Only primary glioma specimens were included in this study. We enrolled 11 patients histologically diagnosed with low-grade glioma (grade I, $n=1$; grade II, $n=10$ ) and 22 patients with high-grade glioma (grade III, $n=11$; grade IV, $\mathrm{n}=11)$ in this study. As a control group $(\mathrm{n}=10)$, the cerebral tissues which were obtained from the patients who underwent surgery for hematoma or tumor and the pathological reports confirmed the absence of tumor or vasculopathy, were used.

\section{Immunohistochemistry}

An independent pathologist re-evaluated all pathological preparations. The ELA antibody (ELA primary antibody, H-00719, 1/200; Phoenix Pharmaceuticals, Inc., CA, USA) was applied to 4-6- $\mu \mathrm{m}$-thick sections obtained from paraffin blocks. All preparations were evaluated and photographed using a light microscope (Leica DFC295, Germany). Histoscores were calculated using the distribution (0.1: $<25 \%$; $0.4: 26 \%-50 \%$; 0.6 : $51 \%-75 \%$; 0.9: $76 \%-100 \%$ ) and intensity (0: no staining; +0.5 : very little staining; +1 : little staining; +2 : medium; +3 : very strong) of staining immunoreactivity (histoscore $=$ distribu tionxintensity).

\section{Statistical Analysis}

The data were determined as mean and standard deviation. Statistical analysis was conducted using SPSS v.22 package program. An independent sample t-test was used for twopoint inter-group assessments, whereas one-way analysis of variance was used for the other assessments. $p<0.05$ was considered statistically significant.

\section{RESULTS}

The results of immunohistochemical staining for ELA immunoreactivity using light microscopy revealed ELA immunoreactivity in the neurons and glial cells of the control brain tissue (Figure 1A, B). The histoscores of the control brain tissue, low-grade glioma tissue, and high-grade glioma tissue were $0.08,0.37$, and 0.92 , respectively (Table I). Compared with the control brain tissue, we observed a statistically significant difference in ELA immunoreactivity in low-grade glioma tissue (Figure 1C-E) and high-grade glioma tissue (Figure $1 \mathrm{~F}-\mathrm{K})(\mathrm{p}<0.05)$. In addition, a statistically significant increase was observed in ELA immunoreactivity in high-grade glioma tissue compared with that in low-grade glioma tissue (Figure 2, Table I) $(p<0.05)$. However, there were no differences in ELA immunoreactivity between anaplastic astrocytomas and glioblastomas (GBMs).

\section{DISCUSSION}

Although primary malignant CNS tumors are reported in $2 \%$ of all cancers, morbidity and mortality rates do not concur. Reportedly, malignant CNS tumors are the leading cause of mortality in children and are the third most common cause of cancer-related deaths in adolescents and adults aged 1534 years (8). However, they are most commonly reported in patients aged above 45 years (23).

The World Health Organization (WHO) grades gliomas as IIV based on their malignant behavior. The main histological types of gliomas in adults are astrocytomas (grades I-IV), oligodendrogliomas (grades II-III), and oligoastrocytomas (grades II-III). GBMs (grade IV) are the most common gliomas reported in adults, whereas supratentorially located low-grade gliomas are the most common in children (4). In addition, meningiomas (30\%) are the most common benign tumors, and GBMs (20\%) are the most frequent malignant tumors among primary CNS tumors. Reportedly, gliomas account for $40 \%$ of all CNS tumors and $78 \%$ of malignant CNS tumors $(5,26)$.

Pilocytic astrocytomas constitute $2 \%-6 \%$ of CNS tumors, with the cerebellum, optic region, brain stem, and infundibulum as the residential areas. Histopathologically, the biphasic pattern of the tumor creates compact and loose areas (25) where mitosis is minimal or absent. In addition, the Ki-67 proliferation index is $<1 \%$ in pilocytic astrocytomas (35). Diffuse astrocytomas account for $10 \%$ of all gliomas and are more common in males aged $30-40$ years. They are often supratentorial, frontal, and temporal. Histopathological examination reveals well-differentiated neoplastic fibrils and gemistocytic astrocytes in a microcystic tumor matrix. It exhibits more cellular and nuclear atypia than the normal brain tissue. Furthermore, mitotic activity is usually absent or minimal $(25,33)$.

Anaplastic astrocytomas are grade III tumors, as classified by the WHO, located in the cerebral hemispheres similar to diffuse astrocytomas. Histopathologically, there is diffuse increased cellularity, nuclear atypia, and marked mitotic 




Figure 1: A) Hematoxylin-eosin (H\&E X400) and B) immunohistochemical staining of control brain tissue (X400), C) post-contrast image of diffuse astrocytoma case, D) H\&E of diffuse astrocytoma (X400), E) immunohistochemical staining of diffuse astrocytoma (X400), F) post-contrast image of anaplastic astrocytoma case, G) H\&E of anaplastic astrocytoma (X100), H) immunohistochemical staining of anaplastic astrocytoma (X400), I) post-contrast image of glioblastome multiforme case, J) H\&E of glioblastome multiforme (X100) and K) immunohistochemical staining of glioblastome multiforme (X400) (black arrows: ELABELA immunoreactivity). 
Table I: Elabela Immunoreactivity of Tissues with Statistical Analysis

\begin{tabular}{|c|c|c|c|c|}
\hline \multirow{2}{*}{ Tissues } & \multicolumn{3}{|c|}{ Histoscore } & \multirow[t]{2}{*}{$\mathbf{p}$} \\
\hline & Neuronal cells & Glial cells & Tumor Cell & \\
\hline Control & $0.09 \pm 0.15$ & $0.08 \pm 0.13$ & - & \\
\hline Low-grade gliomas & \multicolumn{2}{|c|}{-} & $0.37 \pm 0.11^{a}$ & 0.001 \\
\hline
\end{tabular}

a: compared with control, b: compared with low-grade, values are given as mean \pm standard deviation.

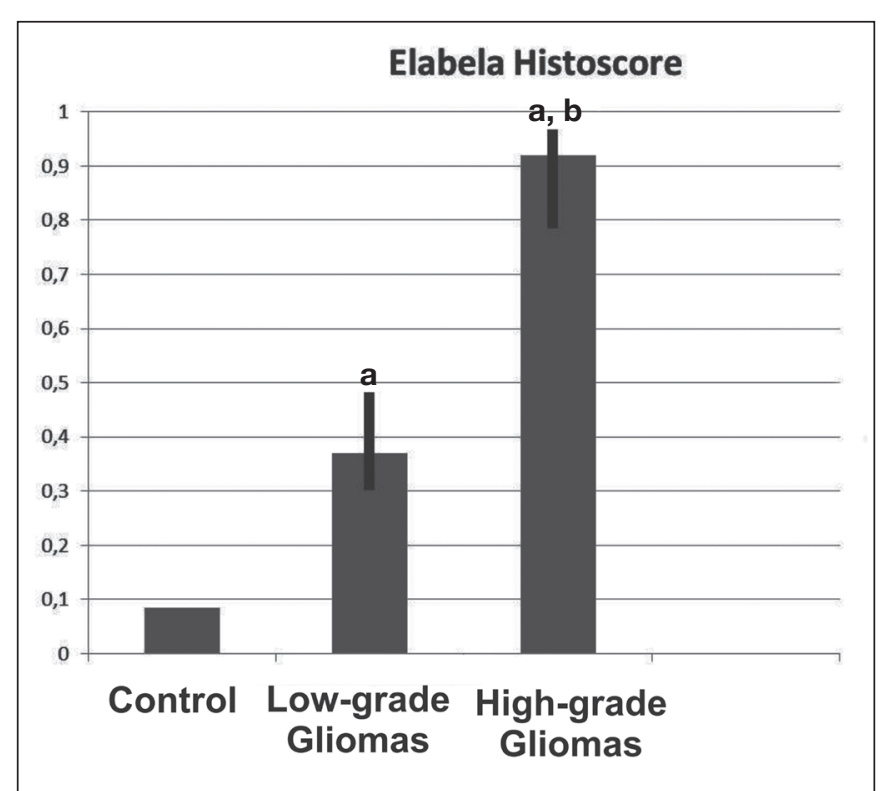

Figure 2: ELABELA histoscores of control brain tissue and glioma tissues.

activity. Abnormal mitotic activity is present; however, no microvascular proliferation and necrosis are reported. Anaplastic astrocytomas may progress to GBMs $(25,33)$. GBMs are WHO grade IV tumors and the most prevalent brain tumors and malignant gliomas (5), with central necrosis in $80 \%$ of the tumor mass. GBMs are poorly differentiated anaplastic cellular gliomas that comprise pleomorphic astrocytic tumor cells with marked mitotic activity and nuclear atypia. While both microvascular proliferation and necrosis are diagnostic, tumor necrosis is an essential feature of GBMs that indicates aggressive behavior $(25,33)$.

In this study, we assessed 11 patients with a histologically verified low-grade glioma (grade $\mathrm{I}, \mathrm{n}=1$; grade $\mathrm{I}, \mathrm{n}=10$ ) and 22 with a histologically verified high-grade glioma (grade III, $\mathrm{n}=11$; grade IV, $\mathrm{n}=11$ ), based on the WHO classification (26). The histoscores of the control brain tissue, low-grade glioma tissue, and high-grade glioma tissue were 0.08, 0.37, and 0.92 , respectively. We observed increased immunoreactivity in low-grade glioma tissues compared with that in control brain tissues. In addition, the increase of ELA immunoreactivity in high-grade gliomas was higher than that in low-grade gliomas, which exhibits the importance of vascular proliferation and of ELA as its activator.

ELA is a peptide containing 54 amino acids, including a secretory signal with a mature form containing 32 amino acids, and its transcripts are found in human pluripotent stem cells, kidney, and prostate (7). Wang et al. investigated the functionality of ELA and its relationship with AR signaling in the mammalian system. They demonstrated that ELA is expressed in human embryonic stem cells, induced pluripotent stem cells, and adult kidney tissue. In addition, they supported that ELA is a natural hormone in the human system that functions during and after embryonic development (38). Both $\mathrm{AR}$ and apelin are expressed in some tissues such as those of the heart, lungs, vascular endothelium, kidneys, and brain. Studies have demonstrated that the apelinergic system has a broad range of biological functions such as homeostasis of the cardiovascular system and fluid metabolism $(6,10)$. Apelin is an endogenous ligand of the GPCR, with some isoforms such as apelin-36, apelin-17, and apelin-13 (27,32). Apelin and AR are widely expressed in many types of cells and tissues such as neurons, glial cells, hypothalamic tissues, colonic tissues, and skeletal muscle (28). Reportedly, apelin stimulates the proliferation and migration of retinal endothelial cells (18). A study investigating the role of apelin in diabetic retinopathy demonstrated a high vitreous concentration of apelin in the eyes of patients with proliferative diabetic retinopathy, as shown by immunofluorescence staining of apelin in the endothelial cells of the fibrovascular membranes (36).

Hao et al. demonstrated that high AR expression was significantly associated with higher rates of tumor invasion and local lymph node and distant metastasis in gastric cancer (11). Currently, clinically approved angiogenesis inhibitors primarily target the VEGF signaling pathway, thereby inhibiting tumor vascularization $(3,39)$. The overexpression of apelin and its receptor is further detected in highly proliferating microvessels in primary GBM tissues compared with that in normal brain tissues (16). A recent and important study regarding the apelinergic system and glioma growth reported by Harford-Wright et al. concluded that apelin is a critical factor in glioma growth (12). In addition, the authors concluded that inhibition of the apelinergic system is associated with a reduction in tumor volume, vascularization, and proliferation and an increase in apoptosis. This study also supports the results and proposed 
pathophysiological mechanism of our study. Although there are some studies that have reported the association between the interaction of ELA and the apelinergic system, to the best of our knowledge, our current study is the first to report the aggressivity of gliomas and the role of ELA in this behavior.

\section{CONCLUSION}

ELA has an angiogenetic role in the progression of glial tumors. ELA, which is an endogenous ligand of the AR, activates the apelinergic system and causes the progression of glial tumors. Further studies with a large number of patients are necessary to investigate the angiogenetic role of ELA and apelin in glial tumors.

\section{ACKNOWLEDGEMENT}

Preparation for publication of this article is partly supported by Turkish Neurosurgical Society.

\section{REFERENCES}

1. Alfarano C, Foussal $C$, Lairez $O$, Calise D, Attané $C$, Anesia R, Daviaud D, Wanecq E, Parini A, Valet P, Kunduzova O: Transition from metabolic adaptation to maladaptation of the heart in obesity: Role of apelin. Int J Obes (London) 39:312320, 2015

2. Azizi M, Iturrioz X, Blanchard A, Peyrard S, De Mota N, Chartrel $\mathrm{N}$, Vaudry H, Corvol P, Llorens-Cortes C: Reciprocal regulation of plasma apelin and vasopressin by osmotic stimuli. J Am Soc Nephrol 19:1015-1024, 2008

3. Bergers G, Benjamin LE: Tumorigenesis and the angiogenic switch. Nat Rev Cancer 3: 401-410, 2003

4. Bristol RE: Low-grade glial tumors: Are they all the same? Semin Pediatr Neurol 16:23-26, 2009

5. Buckner JC, Brown PD, Brian P: Central Nervous System Tumors. Symposium on solid tumors. Mayo Clin Proc 82: 1271-1286, 2007

6. Chapman NA, Dupré DJ, Rainey JK: The apelin receptor: Physiology, pathology, cell signalling, and ligand modulation of a peptide-activated class A GPCR. Biochem Cell Biol 92: 431-440, 2014

7. Chng SC, Ho L, Tian J, Reversade B: ELABELA: A hormone essential for heart development signals via the apelin receptor. Dev Cell 27:672-680, 2013

8. Department of Health and Human Services, Centers for Disease Control and Prevention (CDC), National Program of Cancer Registry of the United States. https://www.cdc.gov/ cancer/dcpc/data/index.htm (Accessed August 15, 2017)

9. El Messari S, Iturrioz X, Fassot C, De Mota N, Roesch D, Llorens-Cortes C: Functional dissociation of apelin receptor signaling and endocytosis: Implications for the effects of apelin on arterial blood pressure. J Neurochem 90:1290-1301, 2004

10. Galanth C, Hus-Citharel A, Li B, Llorens-Cortès C: Apelin in the control of body fluid homeostasis and cardiovascular functions. Curr Pharm Des 18: 789-798, 2012
11. Hao $Y Z$, Li ML, Ning FL, Wang XW: APJ is associated with treatment response in gastric cancer patients receiving concurrent chemoradiotherapy and endostar therapy. Cancer Biother Radiopharm 32:133-138, 2017

12. Harford-Wright E, Andre-Gregoire G, Jacobs KA, Treps L, Le Gonidec S, Leclair HM, Gonzalez-Diest S, Roux Q, Guillonneau F, Loussouarn D, Oliver L, Vallette FM, Foufelle F, Valet P, Davenport AP, Glen RC, Bidere N, Gavard J: Pharmacological targeting of apelin impairs glioblastoma growth. Brain 140:2939-2954, 2017

13. Hinrichs BH, Newman S, Appin CL, Dunn W, Cooper L, Pauly R, Kowalski J, Rossi MR, Brat DJ: Farewell to GBM-O: Genomic and transcriptomic profiling of glioblastoma with oligodendroglioma component reveals distinct molecular subgroups. Acta Neuropathol Commun 4:4, 2016

14. Holland EC: Glioblastoma multiforme: The terminator. Proc Natl Acad Sci USA. 97:6242-6244, 2000

15. Jubb AM, Hurwitz HI, Bai W, Holmgren EB, Tobin P, Guerrero AS, Kabbinavar F, Holden SN, Novotny WF, Frantz GD, Hillan $\mathrm{KJ}$, Koeppen $\mathrm{H}$ : Impact of vascular endothelial growth factor-A expression, thrombospondin-2 expression, and microvessel density on the treatment effect of bevacizumab in metastatic colorectal cancer. J Clin Oncol 24:217-227, 2006

16. Kalin RE, Kretz MP, Meyer AM, Kispert A, Heppner FL, Brandli AW: Paracrine and autocrine mechanisms of apelin signaling govern embryonic and tumor angiogenesis. Dev Biol 305:599614,2007

17. Kaplan M, Koparan M, Sari A, Ozturk S, Kaplan SK, Erol FS: Can behenic acid (C22:0) levels be a prognostic factor in glial tumors? Can J Neurol Sci 40:854-856, 2013

18. Kasai A, Shintani N, Oda M, Kakuda M, Hashimoto H, Matsuda T, Hinuma S, Baba A: Apelin is a novel angiogenic factor in retinal endothelial cells. Biochem Biophys Res Commun 325:395-400, 2004

19. Kawamata Y, Habata Y, Fukusumi S, Hosoya M, Fujii R, Hinuma S, Nishizawa N, Kitada C, Onda H, Nishimura O, Fujino M: Molecular properties of apelin: Tissue distribution and receptor binding. Biochim Biophys Acta 1538:162-171, 2001

20. Kidoya $\mathrm{H}$, Naito $\mathrm{H}$, Takakura N: Apelin induces enlarged and nonleaky blood vessels for functional recovery from ischemia. Blood 115:3166-3174, 2010

21. Kidoya H, Ueno M, Yamada Y, Mochizuki N, Nakata M, Yano T, Fujii R, Takakura N: Spatial and temporal role of the apelin/ APJ system in the caliber size regulation of blood vessels during angiogenesis. EMBO J 27:522-534, 2008

22. Kuba K, Zhang L, Imai Y, Arab S, Chen M, Maekawa $Y$, Leschnik M, Leibbrandt A, Markovic M, Schwaighofer J, Beetz N, Musialek R, Neely GG, Komnenovic V, Kolm U, Metzler B, Ricci R, Hara H, Meixner A, Nghiem M, Chen X, Dawood F, Wong KM, Sarao R, Cukerman E, Kimura A, Hein L, Thalhammer J, Liu PP, Penninger JM: Impaired heart contractility in apelin gene-deficient mice associated with aging and pressure overload. Circ Res 101:e32-e42, 2007

23. Levin A, Gutin PH: Neoplasms of the central nervous system. De Vita VT, Hellman S, Rosenberg SA (eds). Cancer Principle and Practice of Oncology, 4th edition, Philadelphia: J.B Lippincott-Raven Publishers pp 2022- 2083, 1997 
24. Liu Q, Hu T, He L, Huang X, Tian X, Zhang H, He L, Pu W, Zhang L, Sun H, Fang J, Yu Y, Duan S, Hu C, Hui L, Zhang H, Quertermous T, Xu Q, Red-Horse K, Wythe JD, Zhoua $\mathrm{B}$ : Genetic targeting of sprouting angiogenesis using AplnCreER. Nat Commun 6:6020, 2015

25. Louis DN, Ohgaki H, Wiestler OD, Cavenee WK, Burger PC, Jouvet A, Scheithauer BW, Kleihues P: WHO classification of tumors of the central nervous system, 2007. Acta Neuropathol 114: 97-109, 2007

26. Louis DN, Perry A, Reifenberger G, von Deimling A, FigarellaBranger D, Cavenee WK, Ohgaki H, Wiestler OD, Kleihues P, Ellison DW: The 2016 World Health Organization classification of tumors of the central nervous system: A summary. Acta Neuropathol 131: 803-820, 2016

27. Maguire JJ, Kleinz MJ, Pitkin SL, Davenport AP: (Pyr1) Apelin-13 identified as the predominant apelin isoform in the human heart: Vasoactive mechanisms and inotropic action in disease. Hypertension 54:598-604, 2009

28. Medhurst $A D$, Jennings $C A$, Robbins MJ, Davis RP, Ellis C, Winborn KY, Lawrie KW, Hervieu G, Riley G, Bolaky JE, Herrity NC, Murdock P, Darker JG: Pharmacological and immunohistochemical characterization of the APJ receptor and its endogenous ligand apelin. J Neurochem 84:11621172,2003

29. O'Dowd BF, Heiber M, Chan A, Heng HH, Tsui LC, Kennedy JL, Shi X, Petronis A, George SR, Nguyen T: A human gene that shows identity with the gene encoding the angiotensin receptor is located on chromosome 11. Gene 136, 355-360, 1993

30. Pauli A, Norris ML, Valen E, Chew GL, Gagnon JA, Zimmerman S, Mitchell A, Ma J, Dubrulle J, Reyon D, Tsai SQ, Joung JK, Saghatelian A, Schier AF: Toddler: An embryonic signal that promotes cell movement via Apelin receptors. Science 343:1248636, 2014
31. Picault FX, Chaves-Almagro C, Projetti F, Prats $H$, Masri B, Audigier Y: Tumour co-expression of apelin and its receptor is the basis of an autocrine loop involved in the growth of colon adenocarcinomas. Eur J Cancer 50:663-674, 2014

32. Pitkin SL, Maguire JJ, Bonner TI, Davenport AP: International Union of Basic and Clinical Pharmacology. LXXIV. Apelin receptor nomenclature, distribution, pharmacology, and function. Pharmacol Rev 62:331-342, 2010

33. Prayson RA: Neuropathology ( $2^{\text {nd }}$ edition). Atlanta: Elsevier \& Saunders, 2011

34. Sawane M, Kajiya K, Kidoya H, Takagi M, Muramatsu F, Takakura N: Apelin inhibits diet-induced obesity by enhancing lymphatic and blood vessel integrity. Diabetes 62:1970-1980, 2013

35. Sengupta S, Chatterjee U, Banerjee U, Ghosh S, Chatterjee S, Ghosh AK: A study of histopathological spectrum and expression of Ki-67, TP53 in primary brain tumors of pediatric age group. Indian J Med Paediatr Oncol 33: 25-31, 2012

36. Tao Y, Lu Q, Jiang YR, Qian J, Wang JY, Gao L, Jonas JB: Apelin in plasma and vitreous and in fibrovascular retinal membranes from patients with proliferative diabetic retinopathy. Invest Ophthalmol Vis Sci 51: 4237-4242, 2010

37. Tatemoto K, Hosoya M, Habata Y, Fujii R, Kakegawa T, Zou MX, Kawamata Y, Fukusumi S, Hinuma S, Kitada C, Kurokawa $\mathrm{T}$, Onda H, Fujino M: Isolation and characterization of a novel endogenous peptide ligand for the human APJ receptor. Biochem Biophys Res Commun 251:471-476, 1998

38. Wang Z, Yu D, Wang M, Wang Q, Kouznetsova J, Yang R, Qian K, Wu W, Shuldiner A, Sztalryd C, Zou M, Zheng W, Gong DW: Elabela-apelin receptor signaling pathway is functional in mammalian systems. Sci Rep 5: 8170, 2015

39. Zhang L, Takara K, Yamakawa D, Kidoya H, Takakura N: Apelin as a marker for monitoring the tumor vessel normalization window during antiangiogenic therapy. Cancer Sci 107:36-44, 2016 